\title{
DESCOLONIZAR O PODER: REVERBERAÇÕES DE FOUCAULT EM MBEMBE. (NEOLIBERALISMO + BIOPOLITICA + GOVERNAMENTALIDADE = NECROPOLITICA MUNDIAL)
}

\author{
Jose Luiz Silva da Costa $^{1}$ \\ Leticia Lucindo Queiroz ${ }^{2}$
}

\begin{abstract}
RESUMO: Este artigo discute a passagem, nos tempos atuais, da biopolítica a necropolítica, isto é, de uma política da sujeição dos grupos sociais até o extermínio (desdobramento do estado de exceção) destes povos. O Estado e suas formas de governo, em sua maioria caracterizada pelo neoliberalismo são os responsáveis por esse modelo de gestão social. Utilizaremos as obras e teses de Michel Foucault e Achille Mbembe a fundamentação. Para Mbembe, em sua descrição biopolítica, uma das características mais visíveis e alarmante dos últimos tempos (passando pelas duas grandes guerras e hoje exposto em conflitos político-territoriais generalizados) é a violência e o extermínio de povos, indivíduos, grupos étnicos, minorias sociais etc. Em Foucault, esta temática é elucidada a partir das relações de micro poderes que formam uma ampla teia de relações denominadas governabilidade que se apresentam nas formas das dominações econômica e biológica (gestão sobre os corpos, a vida e a morte). Para compreender esse fenômeno político e social, a partir de nossos autores, é fundamental perceber a ação da crise global que perpassa o planeta e as estruturas sociais que se assenta na forma do desgaste do modelo socioeconômico denominado capitalismo, nas suas vertentes de modelos de governo, como o neoliberalismo, bem como das estruturas disciplinares que o formatam e o sustentam.
\end{abstract}

Palavras chaves: Governamentalidade. Biopolítica. Necropolítica.

\begin{abstract}
This article discusses the passage, in current times, from biopolitics to necropolitics, in other words, from a politics of subjection of social groups to the extermination (unfolding of the state of exception) of these people. The government and its forms of governance, in their majority characterized by neoliberalism, are responsible for this model of social management. Michel Foucault and Achille Mbembe's work will serve as the theoretical framework for this thesis. For Mbembe, in his biopolitical description, one of the most visible and alarming characteristics of recent times (passing through the two great wars and today exposed in generalized political-territorial conflicts) is the violence and extermination of peoples, individuals, ethnic groups, social minorities, etc. In Foucault's work, this issue is elucidated from the relations of micro powers that form a wide web of relations called governability that present themselves in the forms of economic and biological domination (management over bodies, life, and death). To understand this political and social phenomenon, from these authors' stand points, it is fundamental to perceive the action of the global crisis that pervades the planet and the social structures that are based on the form of wear and tear of the socioeconomic model
\end{abstract}

\footnotetext{
${ }^{1}$ Graduado e Mestre em Filosofia, na linha de Ética e Filosofia pela Política Universidade Federal do Ceará (UFC). Doutorando em Filosofia, na linha de Filosofia Política pela Universidade Federal do Rio Grande do Norte (UFRN). Professor do IFRN - Instituto Federal do Rio Grande do Norte. Email:1uiz.jose@ifrn.edu.br.

${ }^{2}$ Graduada em bacharelado em Humanidades e graduanda em Antropologia pela Universidade da Integração Internacional da lusofonia Afro-Brasileira (UNILAB).Email: leticialucindo@outlook.com
} 
called capitalism, in its aspects of models of government such as neoliberalism, as well as the disciplinary structures that shape and sustain it.

Key-words: Govermentality. Biopolitic. Necropolitic.

\section{INTRODUÇÃO}

O pensamento de Foucault foi de fundamental importância em suas décadas e reverberam espantosamente em nosso tempo, para pensarmos de forma precisa a influência dos micropoderes e das estruturas disciplinares que nos cercam e moldam nossas cognições e ações. Foucault, ao perceber que o poder está entranhando em todas as relações sociais e se manifesta desde os discursos até as práticas disciplinares, nos lega uma perspectiva de pensamento que descortina os tempos sombrios pelos quais passamos, onde em diversas nações do mundo o estado de exceção (os discursos de ódio, a violência social e estatal) se tornaram regras. Achille $\mathrm{Mbembe}^{3}$, também reflete a realidade dos últimos períodos que vivemos afirmando que as estruturas políticas se transformaram em uma máquina de aniquilar grupos e indivíduos, ou seja, a política se traduz hoje em Necropolítica.

Foucault, nos alerta de que o poder e o biopoder, fim último da política e base das sanções disciplinares modernas e contemporâneas, estão na base de todas as relações sociais, e como tal, implicam nas mais diversas manifestações subjetivas e em todas as relações intersubjetivas. Mbembe, também percebe, de igual maneira, que o biopoder está na base das sujeições humanas e das políticas de morte que daí resultam. Desta forma podemos perceber que nossos pensadores podem fazer uma importante contribuição ao atual debate acerca da questão da invisibilização e extermínio de povos no mundo.

Queremos compreender a relação entre a obra de Mbembe com as teses do biopoder e da governamentalidade foucaultianas da década de 70, onde surgem os textos Vigiar e Punir (1975), Em Defesa da Sociedade (1975-1976), Segurança, Território e População (1977-1978) e Nascimento da Biopolítica (1978-1979), pois são nestes textos ${ }^{4}$ que o genealogista aponta os dispositivos de conformação das massas populares à sociedade do controle e ao neoliberalismo. A partir daí, nos

\footnotetext{
${ }^{3}$ É um pensador e professor camaronês e uma referência académica no estudo do pós-colonialismo, está engajado em pensar as grandes questões da história, filosofia e da política.

${ }^{4}$ Importante tomar conhecimento do excerto Microfisica do poder (1979) onde se analisa no capítulo XVII intitulado: a governamentalidade, e trechos da obra História da sexualidade: a vontade de saber (1976), estes nos auxiliam a compreender as vertentes de pensamento de Foucault que tratam do biopoder em áreas diversas da humanidade.
} 
propomos a analisar a constituição e transformação, em Foucault, do poder (biopoder) desde a arte de disciplinar, a biopolítica até a fase do governo da sociedade, nesta fase determinada como genealógica, e verificar se há um paralelo na recepção de sua crítica da análise decolonial de Mbembe sobre a necropolítica nos dias atuais. Assim queremos descobrir as rupturas e continuidades de pensamento de um autor a outro, e perceber como a biopolítica se transformou em necropolítica.

\section{FOUCAULT: PODER, BIOPODER E GOVERNAMENTALIDADE.}

Nos escritos da década de 1970 Foucault desenvolve uma vigorosa análise das mecânicas e teias das relações de poder, indo além dos pressupostos das teorias políticas de sua época e inaugurando uma jornada pelas trajetórias das tecnologias de poder. Foucault identifica que há um poder que leva ao direito de matar (poder soberano). Esse direito sempre é reivindicado por governos e indivíduos que ao exercerem o ato da soberania se proclamam como legisladores e executores desta máxima vital. Tal poder já era identificado no direito romano que permitia em caso de guerra ou ameaça ao soberano o poder de aniquilar outrem.

Foucault aponta que na passagem do século XVII ao XIX o poder assume a vida como seu maior instrumento de manipulação (levando em consideração o contexto de domínio da vida já exercidos pelo colonialismo e racimo), o que se traduz em biopolítica, esta forma de poder que atua diretamente sobre os corpos dos indivíduos pelo manejo de técnicas disciplinares, aumentando a produtividade destes. No desdobrar do aumento do controle biopolítico as técnicas são aprimoraradas e alargadas para todo o conjunto da sociedade, a população (manifestadamente no controle da saúde e da segurança). Assim, a biopolítica toma a partir dos dispositivos de segurança, território e medicalização a tarefa de indicar quem pode viver e quem pode morrer.

Esta biologização da política era exercida em séculos passados no mundo do trabalho e nas prisões de forma peculiar (pelas altas carga de trabalho e punições), mas os seus aprimoramentos fizeram suas capacidades de manipular taxas de fecundidade, taxas de morbidade, ser o setor responsável pela higienização dos espaços públicos e da saúde do povo, bem como controlar a violência através da segurança pública o que elevou o poder soberano dos Estados de forma tal que hoje podemos classificar nosso tempo conforme Foucault de "estatização do biológico", com o quase que total controle das vidas das populações. Segundo Branco (2018, p. 85): “A biopolítica, enfim, trata da população e tem no povo, enquanto objeto biológico passível de intervenção política e governamental, um eixo de observação e intervenção de extrema importância”. 
O problema do poder governamental antes exercido sob a égide do direito divino de governar toma novas formas nos séculos atuais sobre o controle social advindos da administração econômicas e políticas neoliberais. Em última instância, o que está em jogo é a gestão das vidas e mortes, o que caracterizamos como a administração biológica social. A política toma a vida de assalto e a controla através dos fenômenos biológicos, e desta forma o controle da vida exercido por neoliberais e soberanos os coloca em um trabalho em favor da morte. O que se tem na gestão social neoliberal biopolítica é o gerenciamento a produção de mortes e terrorismo voltados a determinados setores sociais, projetando desta forma um grande darwinismo social. Para Gefael:

\footnotetext{
Las tácticas que el Estado utiliza para conseguir que los «incluidos» lleven a cabo sus tareas creyendo que son buenas, necesarias y que se corresponden con su papel, son las mismas que estos «incluidos» utilizan para controlar a los «excluidos»: la sutil violencia de la tolerancia, la manipulación del lenguaje, la despolitización a través de la individualización de los problemas socioeconómicos y también etiquetar, culpabilizar, vigilar y amenazar. (GEFAEL, 2015, p. 61).
}

Cabe ressaltar que o direito de matar ou deixar morrer englobam uma série de fatores que ocasionam a morte de indivíduos ou grupos sociais, tais como: a migração forçada, a perca de direitos básicos (saúde, moradia e alimentação), o incremento do risco de morte, as guerras e a morte política. Assim, temos que o Estado e os governos podem matar ou deixar morrer, podem aniquilar ou expor ao aniquilamento.

A biologização da vida serviu nos últimos séculos para legitimar a tentativa de hierarquização entre os grupos sociais e justificar as relações sempre presentes de colonialismo, invasões armadas, discursos de ordem contra a marginalidade, encarceramento em massa, esterilizações forçadas, internações mentais e manter os corpos dóceis e com pouca reação nos trabalhos de exploração perpetuando assim as divisões de classes. Estes discursos com ares darwinistas tentam propagar e enraizar uma teoria evolutiva e hierárquica entre as sociedades contemporâneas afirmando ideais liberais e neoliberais como a liberdade e as vantagens da livre concorrência, as vantagens do empreendorismo e o achamento do Estado nas relações de mercado. Estes discursos reforçam a ideia de há vencedores e vencidos, os visíveis e os invisíveis e, por fim, os grupos sociais que merecem viver e outros que devem desparecer.

A biopolítica toma formas mais acabadas e determinadas para nosso tempo em meados do séc. XIX, momento em que o poder de administração e controle da vida se alça para a gestão das populações. Assim, o que se busca é um mecanismo eficaz de manter uma determinada sociedade disciplinada, docilizada e ordenada, e para tanto os grupos, governos e gerentes do Estado se investem do controle do poder da violência para garantir a segurança interna e externa 
dos possíveis perigos que possam atingir um determinado grupo em um determinado território. Cabendo inclusive aos que que se posicionam na função de gestores sociais o poder condenar e executar normas e punições sobre os indivíduos o próprio território que ofereçam riscos ou sejam classificados como perigosos, anormais ou desordenados.

Para que esse poder se estabeleça e seja absorvida no interior das massas ela deve ser anunciada, repetida e propagada. Ela deve ao mesmo tempo ser uma tecnologia regulamentadora como deve se tornar uma característica normativa e cultual da própria sociedade, para que as práticas de governamentalização (disciplinamento, normatização, legislação e vigilância) se tornem o ethos daquele lugar e para aquelas pessoas.

Para Foucault no decorrer do tempo entre a idade média e a idade moderna você não tem uma mera substituição de formas de controle da soberania, passando pelo disciplinamento, e se efetivando na forma governo. O que se tem na verdade é um triângulo destes fatores - soberania, disciplina e gestão governamental - segundo Foucault (2008: 143) "uma gestão governamental cujo alvo principal é a população e cujos mecanismos essenciais são os dispositivos de segurança."

Ademais Foucault atenta que há uma vinculação no decorrer histórico que liga profundamente a vinculação entre a mudança de paradigma que fez com que a soberania fosse suplantada como problema genérico para dar lugar ao problema das normatização das populações e, assim, ter as sociedades como um campo de intervenção com a finalidade de aprimorar as técnicas de sujeição dos governos. Neste processo a economia tomou a forma isolada de domínio específico da realidade e a economia política, ao mesmo tempo, tomou a forma como a ciência e a técnica de intervenção dos governos sobre as massas populacionais.

Para Foucault, das sociedades modernas em diante, essa tríade: governo, população e economia política estão cada vez mais amalgamadas num processo que reproduz uma mítica de que sempre existiram juntas ${ }^{5}$. E a partir do século XVIII criam uma simbiose que fundamentam as formas de governos neoliberais que gerenciam os contemporâneos estados e baseiam na economia (PIB, Desenvolvimento, importação, industrialização, privatização etc.) as tomadas de decisões sobre o conjunto das políticas públicas ${ }^{6}$. Compreendemos então que as diversas técnicas,

\footnotetext{
${ }^{5}$ Cria-se nos conjuntos das sociedades a ideia de uma mitologia originária da associação umbilical entre economia + governo, e desta forma não poderiam existir outras formas de vida (não tecnicizadas e controladas) com liberdades políticas e desenvolvimentos humanos.

${ }^{6} \mathrm{O}$ conjunto das políticas públicas como moradia, educação, saneamento e segurança são baseadas em cálculos de eficiência econômica e são pensadas a partir da lógica econômico-administrativo, mostrando assim que todas as esferas do modo atual de governar estão submetidos a economia de mercado. Além do que com o fortalecimento do neoliberalismo e aplicação de PPP's (Parceria Público-Privadas) e privatizações diretas se demonstrou como a economia se alça para além das garantias e direitos fundamentais e da vida.
} 
cálculos e ações governamentais através de diversos dispositivos de segurança (prisão, monitoramento, decretos) são vistas, revistas e postas em ação para garantir a continuidade da governamentalidade. Podemos conjecturar que no cálculo: economia X vida, a primeira é super estimada em detrimento da segunda, pois em todas as tomadas de ações estatais-empresariais (tendo em vista que o mundo e os Estados são um grande mercado financeiro) o crescimento e o desenvolvimento são baseados nos percentuais econômicos (dinheiro e produtos).

Assim, nesta fase de sua obra, em 1970, Foucault estabelece um deslocamento das teorias jurídicos-políticos tradicionais modernas que fundam no Estado a centralidade e domínio do poder, deslocando o seu pensamento para a lógica de um funcionamento em rede, que transita em todo corpo social, e em micro escala nos corpos particulares. O poder disciplinar é uma tecnologia que visa submeter o corpo e constitui uma rede com funções extensas e ligadas entre si, constituindo assim a sociedade disciplinar. O poder não é algo estático ou que se exerce de um centro hierárquico tão somente, na verdade, existem, práticas ou relações de poder.

"estes métodos que permitem o controle minucioso das operações do corpo, que realizam a sujeição constante de suas forças e lhes impõem uma relação de docilidade-utilidade, são o que podemos chamar de disciplinas" (FOUCAULT, 2014, p.135).

É desta forma que Foucault em um momento ulterior percebe o desenvolvimento e o avanço das técnicas e dispositivos de controle e aponta que tal estratégia de sujeição e controle passa ao nível da governamentalidade e, nesta fase as estratégias de extermínio (necropolítica) se intensificam e compõem o arcabouço do Estado liberal ${ }^{7}$ e neoliberal (então evidencia-se que há uma transição do biopoder a governamentalidade), e a compreensão de tal transição é parte fundamental para a compreensão da linha que liga o projeto foucaultiano ao uso de Mbembe e seu projeto de crítica dos dispositivos e forças de aniquilação de pessoas, assim elucidando as práticas contemporâneas de sujeição dos corpos, mentes, subjetividades e grupos sociais.

Para Foucault a sujeição dos indivíduos pelo Estado moderno é descrito nesta tríade: desde a 1 - individuação empírica, 2 - a subjetivação, e 3 - reprimindo e manipulando os processos biológicos. Para tal desenvolveu e aprimorou diversas técnicas: 1- dispositivos disciplinares, 2 - infligindo as práticas de introspecção, além da criação de diversos 3 mecanismos de segurança que se transformaram na sociedade do controle. E por fim, a economia do

\footnotetext{
${ }^{7}$ Neste caso, ele está pensando na expansão do capitalismo, na qual este sistema precisa de um número elevado de força de trabalho apta para a produção de mercadorias: fazer do corpo uma máquina de produção, por meio de normas, preceitos e proibições, eliminando desvios e anomalias, eis a função histórica das disciplinas. Desta maneira a prisão, escola, a indústria e os quarteis servirão para a formação e adequação de indivíduos não apenas dóceis (conformados e adequados ao sistema de normas históricas vigentes), mais úteis (em condições máximas de produção e eficiência).
} 
poder liberal, do biopoder disciplinar e do dispositivo panóptico configuraram tais técnicas para: 1 - produzir corpos úteis e dóceis, 2 - confeccionar a produção de sujeitos e 3 - desenvolver a produção de forças vitais (que no decorrer do caminhar histórico se apresentará de maneira ambígua como poder de tirar a vida ou deixar viver). Para Foucault a população e sua gestão de vida e da morte são o mote da biopolítica governamental, e assim, nos interpela:

De que se trata nessa nova tecnologia do poder, nessa biopolítica, nesse
biopoder que está se instalando? Eu lhes dizia em duas palavras agora ha
pouco: trata-se junto de um conjunto de processos como a proporão dos
nascimentos e dos óbitos, a taxa de reprodução, a fecundidade de urna
população etc. São esses processos de natalidade, de mortalidade, de
longevidade que, justamente na segunda metade do século XVIII, juntamente
com urna porção de problemas econômicos e políticos, constituíram, acho eu,
os primeiros objetos de saber e os primeiros alvos de controle dessa biopolítica.
É nesse momento, em todo caso, que se lança mão da medição estatística
desses fenômenos com as primeiras demografias. (FOUCAULT, 2005, p. 286.)

\section{Mbembe: da biopolítica a Necropolítica.}

Mbembe, em seu texto, Necropolítica (2018) nos questiona: "Mas sob quais condições práticas se exerce o pode de matar, deixar viver ou expor à morte? Quem é o sujeito dessa lei? Essa noção de biopoder é suficiente para contabilizar as formas contemporâneas em que o político, por meio da guerra, da resistência ou da luta contra o terror, faz do assassinato do inimigo seu objetivo primeiro e absoluto?” (MBEMBE, 2018, p. 6) Para ele, a guerra é um meio de universalizar e exercer o direito de matar e alcançar a soberania. Portanto, deixar viver ou deixar morrer passa da circunscrição de um processo natural, para um controle biopolitico determinado pelos que constituem as estruturas de dominação. Para desvendar estas estruturas Mbembe indica que é necessário entender o conceito de biopoder e relacioná-los com a questão da soberania e do estado de exceção ${ }^{8}$, já que estes podem ser usados para classificar tanto os Estados nações (livres e soberanos) e os Estados totalitários (livres e soberanos).

Mbembe afirma que a necropolítica se dá relação direta entre três grandes composições que se aliam e são responsáveis pela manutenção das estruturas de poder necroviolentas dos Estados nacionais: biopolítica, soberania e estado de exceção.

Estas três grandes estruturas de poder se aliam para constituir o cenário contemporâneo de uma verdadeira guerra social que pode ser descrita por diversas insígnias e, a depender do local e das condições de seu governo, são caracterizadas por: guerras às drogas, guerra ao terror, guerra de resistência ou defesa da soberania nacional. Por isso, nos interessa descobrir as ressignificações

\footnotetext{
${ }^{8}$ Para uma análise mais profunda cabe investigar, conforme Mbembe, as referências e críticas a partir dos textos de Agamben: Estado exceção (2004) e Homo sacer (2010) e as Origens do Totalitarismo (1989) de Arendt.
} 
e atualizações destes termos na transição para o quadro social e político que temos hoje no mundo. Desta maneira:

Essa noção de biopoder é suficiente para contabilizar as formas contemporâneas em que o político, por meio da guerra, da resistência ou da luta contra o terror, faz do assassinato do inimigo seu objetivo primeiro e absoluto? A guerra, afinal, é tanto um meio de alcançar a soberania como uma forma de exercer o direito de matar. Se considerarmos a política uma forma de guerra, devemos perguntar: que lugar é dado à vida, à morte e ao corpo humano (em especial o corpo ferido ou morto)? Como eles estão inscritos na ordem de poder? (Mbembe, 2018, p. 6)

Nos termos da filosofia politica moderna há uma oposição entre a politica (produto da razão humana) X e a guerra (desrazão, pura ação emotiva e instintiva), isto identifica que os adeptos do contratualísmo e da defesa do Estado acreditam que a formação do Estado civil (que rege as leis e impõem ordem ao caos natural) é movida pela razão, e que a política é o resultado lógico do uso da racionalidade, sendo o processo inverso, isto é a fuga da racionalidade (o fim do diálogo racional) à volta ao estado de barbárie, a retomada do processo de falta de civilidade, por fim a reinserção ao estado de natureza.

Mbembe discorda completamente dos modernos entendendo que este "romance da soberania" criada e propagada pelos estatistas esconde a responsabilização das verdadeiras práticas das soberanias modernas, a saber, um projeto necropolítico que visa a instrumentalização da vida humana e a segregação social baseada em pessoas úteis e pessoas descartáveis. Para ele, os modernos enfatizam que "a razão é a verdade do sujeito, e a política é o exercício da razão na esfera pública", entretanto isto oblitera o desenvolvimento real das formas como a soberania se instalou e tomou forma no mundo pós guerra e nas democracias liberais. Para ele (2018, p.19) Foucault afirma claramente que o "direito soberano de matar (droit de glaive) e os mecanismos de biopoder estão inscritos na forma em que funcionam todos os Estados modernos; de fato, eles podem ser vistos como elementos constitutivos do poder do Estado na modernidade.” Faz parte da constituição do contrato ilimitar o poder soberano do Estado e entroná-lo como o organismo que vai gerir a sociedade, criando o organismo máximo da gerência do biopoder.

A soberania (a forma por excelência de gestão das sociedades atuais) tendem a se transformar em imensas máquina de guerra e heteronomia planejada racionalmente, ela se apresenta sobre a forma de uma normatividade epistemológica planejada que arquiteta as estratégias de sujeição dos grupos sociais, e que ora ataca diretamente e outrora permite ataques contra grupos descartáveis da sociedade. Para tanto, é necessário descortinar, desenvolver e compreender as grandes tecnologias de poder desenvolvidas pelos "donos do poder" que dão sustentação aos estados soberanos, que transformaram as sociedades antes de nós e geraram as nossas sociedades contemporâneas, a saber: o racismo e o colonialismo. 
Estes dispositivos governamentais e paragovernamentais de poder surgem na obra de Mbembe em linhas pormenorizadas para demonstrar as formas práticas e as ideologias que resultam numa política mundial de extermínio e, numa segregação de povos e raças herdadas e, nunca superadas, do legado colonial.

Partindo da perspectiva da periferia deste sistema econômico global que nos assentamos, Mbembe - reapropriando os conceitos e a linha investigativa de Foucault - nos apresenta a proposição de que estes poderes, outrora analisados do micro ao macro, se reconfiguraram (dialeticamente no macro e micro) como o poder de tirar a vida ou deixar viver, o que ele denomina: necropolítica. Percebe-se as linhas tênues da teoria de Foucault sobre o biopoder nas suas reverberações descolonias e periféricas de Mbembe sobre as políticas de extermínio dos tempos atuais. Assim descrito:

$\mathrm{Na}$ formulação de Foucault, o biopoder parece funcionar mediante a divisão entre as pessoas que devem viver e as que devem morrer. Operando com base em uma divisão entre os vivos e os mortos, tal poder se define em relação um campo biológico - do qual toma o controle e se inscreve. (MBEMBE, 2018, p. 17)

Propomos aqui que existe uma apropriação e sobreposição pelo teórico Mbembe das linhas foucaultianas que demonstram a questão da gestão da vida e de sua retirada ser o ápice da governamentalidade. Onde, ele reposiciona este tema pensando e criticizando as sociedades contemporâneas com suas heranças coloniais e bélicas, transformando indivíduos em "não seres" ao modelo do negro na recente África colonial ${ }^{10}$, e os imigrantes que pousam em outros estados fugindo de guerras, desastres naturais, fome, falta de emprego e etc. Cabe-nos aqui também questionar, e a filosofia de modo geral, até onde as teorias filosóficas estão arraigadas de um pensamento colonializante que, disfarçadas de neutralidade científica, reproduzem as táticas de governamentalidades de sujeição dos saberes e dos sujeitos? Pois:

Além disso, experiências contemporâneas de destruição humana sugerem que é possível desenvolver uma leitura da política, da soberania e do sujeito, diferente daquela que herdamos do discurso filosófico da modernidade. Em vez de considerar a razão a verdade do sujeito, podemos olhar para outras categorias fundadoras menos abstratas e mais palpáveis tais como vida e a morte. (MBEMBE, 2018, p. 11)

\footnotetext{
${ }^{9}$ Este termo foi cunhado no texto crítica da razão negra para designar o modelo de gestão do colonizador sobre o colonizado, fazendo-o se sentir inferior e transformando-o em coisa, em máquina.

10 “A espoliação organizada da África se deu quando, em proveito tráfico atlântico (séc. XV ao XIX), homens e mulheres originários de África foram transformados em homens-objectos, homens-mercadoria e homens-moeda. Apesar de a sua vida serem a partir de então a vida e o trabalho dos outros, com quem estavam a viver, mas com quem era interdito ter relações co-humanas, eles deixaram de ser sujeitos ativos.” (MBEMBE, 2017, p. 12).
} 
Esta questão é traçada no campo da crítica filosófica descolonial (chave para compreender os desdobramentos biopolíticos na periferia do capitalismo) pois percebe-se que dois grandes fatores determinaram o ascenso das governamentalidades de extermínio, caracterizados como necropolítica, o $1^{\circ}$ é a colonialidade, e suas permanências desde a modernidade até os dias de hoje, no imaginário popular e em algumas teses filosóficas; e $2^{\circ}$ o racismo que fundamentou um modelo de subdivisão de pessoas onde algumas seriam necessárias e outras úteis, porem descartáveis. Estes dois fatores são poderes que se estendem em rede a uma escala nacional e global e, portanto, reafirmam os prognósticos foucaultianos acerca da biopolítica. Fanon nos dá um retrato da herança epistemológica deixada pelos rastros do colonialismo que geraram essa guerra social contra negros, indígenas, imigrante, palestinos e minorias sociais, onde:

"O colonizador e sua lógica, desumaniza o colonizado. A rigor, animaliza-o. E, de fato, a linguagem do colono, quando fala do colonizado, é uma linguagem zoológica. (...) Essa demografia galopante, essas massas histéricas, esses rostos de onde fugiu qualquer traço de humanidade, esses corpos obesos que não se assemelham mais a nada, esta coorte sem cabeça nem cauda, essas crianças que dão a impressão de não pertencerem a ninguém, essa preguiça estendida ao sol, esse: ritmo vegetal, tudo isso faz parte do vocabulário colonial.” (FANON, 2015, p. 59).

Para Mbembe o objetivo é criar um estado de exceção permanente, que juridicamente e internacionalmente são aceitos ou silenciados. Dentro destas áreas, as populações sofrem um duplo ataque, são impedidas de transitar e vivem segregadas, e em caso de resistências são torturadas e assassinadas. Mbembe classifica como novo Estado de apartheid esta lógica de dividir os territórios ocupados em redes complexas de fronteiras internas subdividas por células isoladas, onde os indivíduos são constantemente monitorados, limitados e subjugados pelas forças da ordem. Como na difícil situação, neste momento, na Venezuela, na Síria, na Faixa de gaza e na Cisjordânia conforme expõe Mbembe:

A ocupação da faixa de Gaza apresenta três características principais ligadas ao funcionamento da formação específica de terror, que chamei de necropoder. A primeira é a dinâmica da fragmentação territorial, o acesso proibido a certas zonas e a expansão de assentamentos. (Mbembe, 2018, p. 43).

O campo de concentração é, por excelência, o território onde se iniciou os projetos necropolíticos que inspiram a racionalidade contemporânea e que foram retransfigurados para o combate a opositores, a dissidentes políticos-ideológicos e a criação de inimigos internos e externos que ameaçam a ordem e a soberania institucional liberal. Apontado por Arendt (2012: 589) como "um horror inalcançado pela imaginação justamente por situar-se fora da vida e da morte." e descrito por Agamben como o espaço no qual se realizou a pior forma de tratamento 
desumano da história, retirando o estatuto político das pessoas e as transformando em puros corpos biológicos manipuláveis e sem valor (objetos irracionais) ${ }^{11}$.

O estado de exceção é uma das características permanentes da herança do terror dos regimes coloniais e das saídas violentas para se resolver as demandas sociais. Para Mbembe esta forma de legislar e exercer o poder soberano se torna nos dias de hoje um estado de exceção permanente, onde o que antes era o escravo se torna o hoje: o desempregado, o imigrante, o favelado, o terrorista e o viciado. E todos com características comuns: a perda do reconhecimento, a falta de direitos sobre seus corpos, a perca do seu estatuto político e de maneira salutar a vulnerabilidade de ser extinto pelo Estado ou pela omissão deste. O que ocorre nestes casos é o desaparecimento do status de cidadão, individuo e pessoa onde se transformam, não mais apenas o negro, mais todos os desafortunados no seio do neoliberalismo e seus governos elitistas em excluídos e assujeitados ao aniquilamento moral, social e físico. Isso transforma a sorte destes desafortunados numa morte já em vida. É fundamental perceber como esta crítica é percebida, a partir, das opções de escolha das gestões governamentais da saúde, da segurança, de crises migratórias, de modificações das legislações trabalhistas e da previdência social $^{12}$.

Apesar de não existirem mais os campos de concentração, ao modelo alemão do reich, permanecem "campos de concentração" nas figuras de imigrantes, sujeitos favelizados, manifestantes torturados, pobres presos, desempregados e subalternizados em geral que estão sob o jugo de um amplo espectro de políticas de destruição humana baseadas em guerras preventivas, onde se transforma as cidades em grandes campos armados e de vigilância permanente, ou numa barbárie social o que no caso do Brasil se confirma nos conflitos urbanos pela disputa de territórios pelo tráfico ou as centenas de mortes pela ação da polícia militar, nos dois casos pela ação ou omissão do Estado. Isso pode ser caracterizado na criação dos poderes

${ }^{11}$ Ver: Agamben, Giorgio: Estado de exceção, São Paulo: Boitempo, 2004 (estado de sítio).

12 Todos os projetos de governos, no caso do Brasil dos últimos 25 anos(FHC, Lula, Dilma, Temer e Bolsonaro), demonstraram, em maior ou menor grau, investimentos massivos nos setores empresariaisindustriais, agrícolas-agronegócio e no setor financeiro (banqueiros) e na mesma medida apresentaram uma série de privatizações de empresas públicas, o alinhamento de parcerias públicos-privados (privilegiando a segunda) e dezenas de reformas agressivas contra os direitos da população (reformas previdenciárias, trabalhistas, fiscais e educacionais).

${ }^{13}$ Ver: Wacquant, L. Punir os pobres: a nova gestão da miséria nos Estados Unidos [A onda punitiva]. Rio de Janeiro: Revan, 2007. 
paralelos (que atuam ora com o Estado e sob sua ordem, e outrora, atuam por fora, com os métodos legais/ilegais e poderes próprios. Assim, Haesbaert afirma:

“O termo 'poder paralelo' (ao poder do Estado), utilizado muitas vezes para caracterizar vários grupos, é muito problemático, pois quase sempre, ainda que de forma ilegal, eles mantem fortes vínculos com o aparelho do Estado. É o caso das milícias em cidades brasileiras, onde um mesmo policial que exerce sua função 'legal' durante o dia pode atuar como milícia privada durante a noite ou nos finais de semana". (HAESBART, 2014:139).

O nomos de diversas sociedades liberais (de forma nítida as que se encontram na periferia do capitalismo globalizado, América latina e África de modo particular) é a necropolítica. A violência paraestatal (milícias, gangues, grupos de extermínio, exércitos privados etc.) e a estatal ${ }^{14}$ são as marcas indeléveis dos tempos históricos que transcorrem.

Não há entre os Estados e seus inimigos “diálogo". $\mathrm{Na}$ verdade, há uma operacionalização permanente do apartheid social que engloba a dialética: cidadão X marginal, bairro X favela, trabalhador X desocupado, manifestante X vândalo; isto legitima as instituições estatais e penais a cercar, coagir e eliminar os inimigos que ela mesmo cria e propaga. No modo de operar biopolítico, há a manutenção e disseminação de discursos racistas, xenófobos, ultra religiosos e anti-ideologicos que alimentam os de dispositivos de segurança e aperfeiçoamento das técnicas de poder para eliminar as vidas que colocam em risco a seguridade e o contínuo biológico das vidas e da propriedade que a ele importa.

\section{CONCLUSÃO}

É perceptível a recepção e reapropriação pela visão mbembeana dos conceitos europeus foucaultianos ${ }^{15}$, para entender a formação da conjuntura política que estamos. Isto vem sendo desenvolvido por diversos autores da filosofia, dentre eles, as ditas teorias pós coloniais (ou

\footnotetext{
${ }^{14}$ Confirma-se nas ações e palavras perpetradas pelo presidente chileno Sebastián Piñera que "após três jornadas de intensos protestos em diferentes lugares do Chile, que até agora deixaram amsi de 20 mortos, o presidente Sebastián Piñera pronunciou-se sobre a atual situação do seu país: Estamos em guerra". Justificando a extrema violência executada, pelas forças policiais, sobre a população chilena que se manifesta pela ampliação dos direitos sociais. In: https://brasil.elpais.com/brasil/2019/10/21/internacional/1571627404_171893.html
}

${ }^{15}$ Percebendo as cruentas diferenças advindas de tempos de pesquisa diferentes, a maneira da abordagem avinda de fatos históricos e de maneira salutar a perspectiva africana e decolonial contemporânea compreendida por Mbembe a partir da questão da tríade racismo, colonialismo, neoliberalismo. 
descoloniais $)^{16}$, que hoje aponta como um de seus expoentes Achile Mbembe. Para ele este modelo de interpretação de mundo atrelado as interpretações críticas dos processos de sujeição e empoderamentos de raças e indivíduos elucida as práticas disciplinares de adequação e eliminação física, bem como das resistências, de sujeitos e massas populares, de forma mais urgente nos conflitos territoriais, étnicos e bélicos nos continentes e países periféricos.

Se para Foucault, a história humana, para muitos a história da razão, nos últimos 2 séculos se baseia no avanço das mais variadas formas de tecnologias de controle social baseadas na governamentalidade e, estas se constituem nas técnicas de controle das populações e indivíduos; Para Mbembe os últimos anos transformaram-se no aprimoramento radical destas tecnologias onde todas as esferas da vida social e politica foram dominadas pela governamentalidade soberana. Pois, foi agora na modernidade que os excessos políticos vêm se transformando em rotina (metamorfoseadas de Républica), e seguido disso geram constantes genocídios, golpes e eliminações com extrema violência. Estamos, portanto, na era da racionalidade bélica, num complexo terrorismo de Estado ${ }^{17}$. Para Foucault (2004, p. 225) a governamentalidade carregou consigo o poder de administrar, regular, articular e planejar a vida social, e impor os seus limites. $\mathrm{Na}$ vertente da soberania política o que se aprendeu foi a dominar e se impor aos cidadãos. A ideia de Estado como órgão estritamente administrativo já foi deixada de lado há tempos, pois este assumiu o caráter de organismo máximo de regulação da vida pela violência e pelo controle, extrapolando o âmbito de governo e assumindo a Necropolítica como a mais avançada forma estatal $^{18}$.

\footnotetext{
${ }^{16}$ Filosofias pós coloniais e decolonias se referem a correntes de pensamentos que se desenvolvem a partir de pensadores africanos e latino americanos que tentam traçar epistemologias do sul, ou seja, uma linha teórica a partir das ideias e das histórias dos povos não europeus e dos sujeitos que outrora foram colonizados. Demonstrando que havia e há pensamento crítico e racional abaixo dos trópicos.

${ }^{17} \mathrm{O}$ que vem ocasionando uma enorme crise de legitimidade política e de representação dentro da democracia liberal descrita por Castells (2017: 5) como: "a autodestruição da legitimidade institucional pelo processo político". Ele assim descreve como o processo mais avassalador dos últimos tempos a ruptura entre governantes e governados. Tal processo emerge da incapacidade de ou, das escolhas governamentais, de lidar com as crises econômicas e sociais através da precarização do trabalho e dos salários, e na mesma vertente através da violência. Pra ele se trata, de um processo sem retorno, do colapso gradual do modelo político de representação e governança (democracia liberal); que outrora foi a saída coletiva para a brutalidade dos estados autoritários, mas que hoje se assenta numa disputa entre partidos que divergem no modo de ação e fala, mas que se inserem e se aproximam na defesa da lógica econômica baseada no desenvolvimentismo.
}

${ }^{18}$ Aquele Leviatã pensado por Hobbes como ente que preservaria a ordem e a segurança dos cidadãos (por meio da violência) tomou a forma do Estado moderno como o poder político que detêm o uso da violência e controla as instâncias de decisão máximas da vida comum. 
Neste interim, os conceitos foucaultianos de governamentalidade e de golpes de Estado são aliados, e servem para desvendar os projetos democrático-liberais que se instalam na maior parte do globo terrestre. Eles são fundamentais para se compreender onde a governamentalidade substituiu as forma arcaicas de governo e no momento seguinte concede as condições de um controle irrestrito das massas populares, para na fase atual se tornar, por um lado, ser o provedor dos mínimos direitos populares, mas em contrapartida uma imensa máquina que escolhe quem deve possuir tais direitos, definindo em última instância quem é cidadão e quem é marginal (descartável).

Desta forma percebemos uma retomada e revisada de Foucault por Mbembe, pois este percebe que o momento ulterior do desenvolvimento e do avanço das técnicas e dispositivos de controle aponta para uma estratégia de sujeição e domínio, e passa do nível da governamentalidade para a fase das estratégias de extermínio (necropolítica), que se intensificam e compõem o arcabouço do Estado liberal ${ }^{19}$ e neoliberal (então evidencia-se que há uma transição do biopoder a governamentalidade, estes entram numa suma simbiose se mesclando em estado de exceção e vigilância permanente, as raízes do necroestado e necrocapitalismo). A compreensão de tal transição é parte fundamental para a compreensão da linha que liga o projeto foucaultiano a leitura contemporânea da realidade global feita por Mbembe e seu projeto de crítica dos dispositivos e forças de aniquilação de pessoas, assim elucidando as práticas contemporâneas de sujeição, controle e eliminação dos corpos, mentes, subjetividades e grupos sociais.

\section{BIBLIOGRAFIA}

AGAMBEN, Giorgio. Homo sacer: o poder soberano e a vida nua. Belo Horizonte: Editora UFMG, 2010.

Estado de exceção, .tradução de Iraci D. Poleti. São Paulo: Boitempo, 2004 (estado de sítio).

ARENDT, Hannah. A Condição Humana. Tradução de Roberto Raposo. Rio de

\footnotetext{
${ }^{19}$ Neste caso, ele está pensando na expansão do capitalismo, na qual este sistema precisa de um número elevado de força de trabalho apta para a produção de mercadorias: fazer do corpo uma máquina de produção, por meio de normas, preceitos e proibições, eliminando desvios e anomalias, eis a função histórica das disciplinas. Desta maneira a prisão, escola, a indústria e os quarteis servirão para a formação e adequação de indivíduos não apenas dóceis (conformados e adequados ao sistema de normas históricas vigentes), mais úteis (em condições máximas de produção e eficiência).
} 
Janeiro: Forense Universitária, 2001.

As origens do totalitarismo. Tradução de Roberto Raposo. São Paulo:

Companhia das Letras, 1989.

Janeiro: Forense Universitária, 2001.

BRANCO, Guilherme Castelo. Terrorismo de Estado. Belo Horizonte: Autêntica, 2013.

Michel Foucault: filosofia e biopolítica. Belo Horizonte: Autêntica, 2015.

Ontologia do presente, racismo, lutas de resistência. In: PASSOS, Izabel C.

Friche, (org.) Poder, normalização e violência: incursões foucaultianas para a atualidade. Belo Horizonte: Autêntica, 2013.

CÉSAIRE, Aimé. Discurso sobre o colonialismo. Tradução de Mario de Andrade. Lisboa: Ed. Paz e Terra, 1979.

CATELLS, Manuel. Ruptura: a crise da democracia liberal. Tradução de Joana Angélica d'Avila Melo. Rio de Janeiro: Zahar, 2018.

FANON, Frantz. Os condenados da terra. Tradução Enilce Albergaria Rocha. Juiz de Fora: Ed. UFJF, 2005.

. Pele negra, máscaras brancas. Tradução de Renato Silveira. Salvador: EDUFBA, 2008.

FOUCAULT, M. Em defesa da sociedade. São Paulo: Martins Fontes, 2005.

A sociedade punitiva: curso no Collège de France (1972-1973). São

Paulo: Editora WMF Martins Fontes, 2015.

História da sexualidade: a vontade de saber. São Paulo: Paz e Terra, 2015.

. La société disciplinaire en crise. In: Dits et Écrits, Tomo 2. Paris: Gallimard, 2001.

Les rapports de pouvoir passent à l'intérieur des corps In: Dits et écrits. Tomo 3. Paris: Gallimard, 1994, p. 228-236.

. Microfísica do poder. Rio de Janeiro: Edições Graal, 1979.

. Vigiar e punir: nascimento da prisão; tradução de Raquel Ramalhete, 42 ed.

Petrópolis, RJ: Vozes, 2014.

GEFAEL, Clara Valverde. De la necropolítica neoliberal a la empatia radical: violencia discreta, cuerpos excluídos y repolitización. Icaria: Spain, 2015.

HAESBART, Rogério. Viver no Limite: território e multi/trasnterritorialidade em tempos de in-segurança e contenção. Rio de Janeiro: Bertand Brasil, 2014. 
HILÁRIO, Leomir Cardoso. Da biopolítica à necropolitica: variações foucaultianas na periferia do capitalismo. Sapereaude, Belo Horizonte, v. 7, n. 12, p. 194-210, Jan./Jun. 2016ISSN: 2177-6342. $\quad$ Disponível em <http://periodicos.pucminas.br/index.php/SapereAude/article/view/P.21776342.2016v7n13p194/9735> Acesso em 21 jun. 2016.

MBEMBE, Achille. Crítica da razão negra. Tradução Marta Lança, Lisboa: Antígona, 2017a. De la postcolonie. Essai sur l'imagination politique dans l'Afrique contemporaine. Paris, Karthala, 2000.

Le politique par le bas en Afrique noire : Contribution à une problématique de la démocratie. Paris, Karthala, 1992 Collection "Les Afriques".

Necropolítica: Biopoder, soberania, estado de exceção política da morte. São Paulo: N-1 edições, 2018.

Politicas da inimizade. Tradução Marta Lança, Lisboa: Antígona, 2017b.

MARX, Karl. O capital: crítica da economia política. Livro I: o processo de produção do capital. São Paulo: Abril Cultural, 1988.

NASCIMENTO, Abdias. O genocídio do povo negro brasileiro: processo de um racismo mascarado. São Paulo: Perspectivas, 2016.

QUIJANO, Anibal. Colonialidade do poder, Eurocentrismo e América Latina. Buenos Aires: CLACSO, Consejo Latinoamericano de Ciencias Sociales, 2005

WACQUANT, L. Punir os pobres: a nova gestão da miséria nos Estados Unidos [A onda punitiva]. Rio de Janeiro: Revan, 2007. 